\title{
Wunderlich--Herlyn--Werner syndrome
}

\section{Kavitha Reddy Kothapally*, Vasantha Kavati, NVR Murthy, Sathyakumar Biswas, Surekha Panditi}

\begin{abstract}
Department of Obstetrics \& Gynaecology, Bhaskar Medical College \& General Hospital, Yenkepally, Moinabad, Telangana, India
\end{abstract}

Received: 22 December 2015

Revised: 23 December 2015

Accepted: 16 January 2016

\author{
*Correspondence: \\ Dr. Kavitha Reddy Kothapally, \\ E-mail: kavitha.nkothapally@gmail.com
}

Copyright: (C) the author(s), publisher and licensee Medip Academy. This is an open-access article distributed under the terms of the Creative Commons Attribution Non-Commercial License, which permits unrestricted non-commercial use, distribution, and reproduction in any medium, provided the original work is properly cited.

\begin{abstract}
A 25 year old married and nulliparous woman with regular menstrual cycles presented with dyspareunia, infertility, increasing dysmenorrhea and recent onset vulval swelling in the gynaec outpatient department at Bhaskar medical college \& Bhaskar General Hospital, Moinabad, Telangana. Gynaecological examination, ultrasound, MRI \& laparoscopy helped in the diagnosis of right hematometrocolpos with noncommunicating right hemivagina,uterus didelphys with absent right kidney and right ureter commonly named as Wunderlich--Herlyn--Werner syndrome or Obstructed Hemivagina with Ipsilateral Renal Agenesis(OHVIRA) syndrome. Left half of uterus, cervix , vagina along with left kidney and ureter were normal. Vaginal septal resection was done draining out the hematometrocolpos and patient's symptoms were relieved. It also improved the chances for fertility. Wunderlich -Herlyn--Werner syndrome or Obstructed Hemivagina and ipsilateral renal agenesis (OHVIRA syndrome) is a rare mullerian anomaly.
\end{abstract}

Keywords: Mullerian anomaly, Hematocolpos, Obstructed hemivagina, Dysparunia, Vaginal septal resection

\section{INTRODUCTION}

Developmental anomalies of Mullerian duct system are mysterious to the gynaecologist. They form a broad spectrum of abnormalities ranging from uterine \& vaginal agenesis, to duplication of uterus \& vagina, to minor uterine cavity abnormalities. They are associated with renal \& axial skeletal abnormalities due to developmental proximity in the intrauterine life. Reported incidence rate varies from $0.2-7.4 \%{ }^{1}$

Uterus didelphys with two separate normal sized halves of uterus with two endocervical canals with fused cervical walls with obstructed hemivagina on right side $\&$ normal left hemivagina is rare. This abnormality along with ipsilateral renal and ureter agenesis is named as Wunderlich-Herlyn--Werner syndrome or obstructed hemivagina with ipsilateral renal agenesis (OHVIRA syndrome). ${ }^{2}$ Workup of these cases includes ultrasonogram and hysterosalpingogram. If these investigations are inconclusive, then MRI and IVP need to be done. ${ }^{5}$

\section{CASE REPORT}

A 25 year old female patient with marital life of $3 y r s$, presented at Bhaskar General Hospital with the complaints of dyspareunia, increasing dysmenorrhea and vulval swelling of 1 week duration. She was hospitalized on $4 / 3 / 15$ for evaluation. She was a nullipara and was anxious to conceive. She attained menarche at 14years of age. Previous menstrual cycles were once in 30-45days with heavy flow for 5 days with mild spasmodic dysmenorrhea. On examination, her general condition was fair with height being $5 \mathrm{ft}$., weight being $43 \mathrm{~kg}$ with feminine body habitus, moderate built \& nourishment. There was no thyromegaly. Breasts were normal. 
On perabdominal examination, lower abdominal obesity was present. External genitalia were healthy. On perspeculum examination, $5 \times 3 \mathrm{cms}$ size vaginal bulge was noted extending along right anterolateral wall, from right lateral fornix upto $2 \mathrm{cms}$ above the introitus. Vaginal mucosa over the swelling appeared intact and was pink in colour. Cervix could not be visualized clearly.

On bimanual examination, vaginal swelling was found to be cystic and extremely tender. Cervix was felt as a small nodule high up in the vagina close to the right anterolateral vaginal swelling. Uterus was normal in size, left hemivagina was free and nontender.

Investigations were done. Hemoglobin was $12.5 \mathrm{gm} \%$. Serum TSH was normal. Blood urea was $24 \mathrm{mg} / \mathrm{dl}$. Serum creatinine was $0.7 \mathrm{mg} / \mathrm{dl}$. Random blood sugar was 103 $\mathrm{mg} / \mathrm{dl}$. Ultrasound showed absent right kidney and ureter with hypoplastic uterus of $4.2 \times 3 \times 2 \mathrm{cms}$ with hyperechoic shadows suggesting blood collection in the right anterolateral vaginal bulge.

MRI pelvis showed uterus didelphys with dilated right sided horn measuring $3.9 \times 2.5 \mathrm{cms}$ and blind ended right hemivagina measuring $5.1 \times 2.3 \mathrm{cms}$ filled with fluid which is hyperintense on $\mathrm{T} 1$ and $\mathrm{T} 2$ weighted images suggesting right hematometrocolpos and normal communicating left hemivagina. Both ovaries were normal.

With the provisional diagnosis of hematocolpos of right hemivagina with normal left hemivagina, case was posted for examination under anaesthesia, diagnostic laparoscopy and septal resection. With foley's catheter in bladder, examination of genitalia under anaesthesia revealed left hemivagina with nulliparous cervix and external os, high up in the vagina with right anterolateral vaginal bulge. Black tarry blood was seen coming out of small pinhole opening in the upper part of right anterolateral vaginal bulge.

Diagnostic laparoscopy was done at the same instance. Pouch of Douglas was free. Both tubes and ovaries were normal. Uterus didelphys with equally two welldeveloped separate horns were visible, each horn measuring approximately $4 \times 3 \times 2 \mathrm{cms}$ in size.

Diagnosis of uterus didelphys with two cervices with hematocolpos of obstructed right hemivagina with patent left hemivagina was made.

Vaginal septal resection of right imperforate/obstructed hemivagina was done. About $15-20 \mathrm{ml}$ of black tarry blood was drained. Hemostasis of vaginal edges was secured. Right cervix could be felt with difficulty as a small nodule, high up in the right hemivagina.

Postoperative period was uneventful. Patient was discharged after 1 week. Patient did not have recurrent swelling or dysmenorrhea/dyspareunia when she came for follow up after 15 days of surgery.

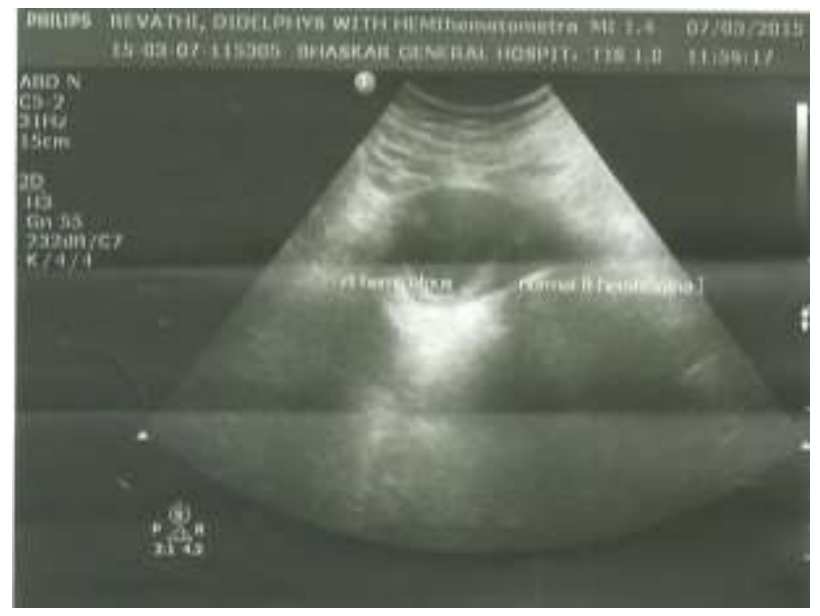

Figure 1: TVS showing right hematocolpos with normal lefthemivagina.

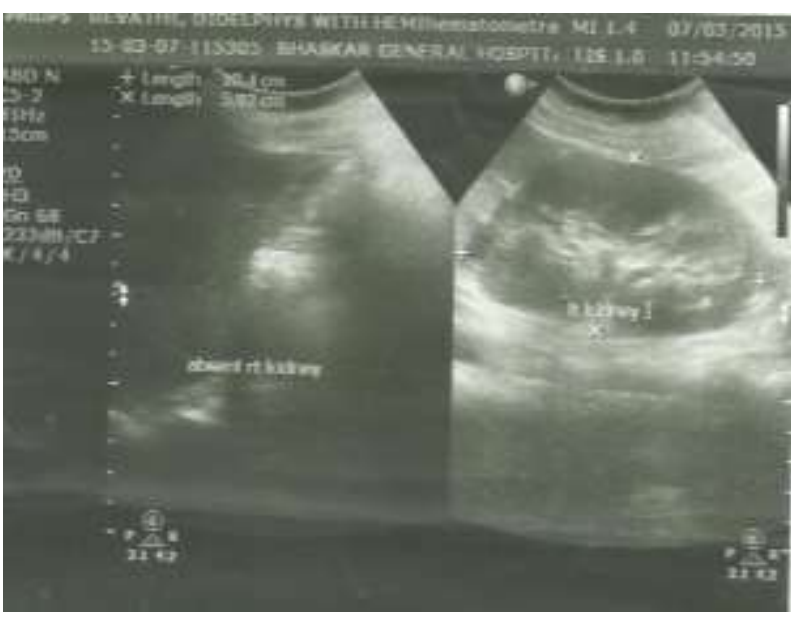

Figure 2: Abdominal ultrasonogram showing absent right kidney and normal left kidney.

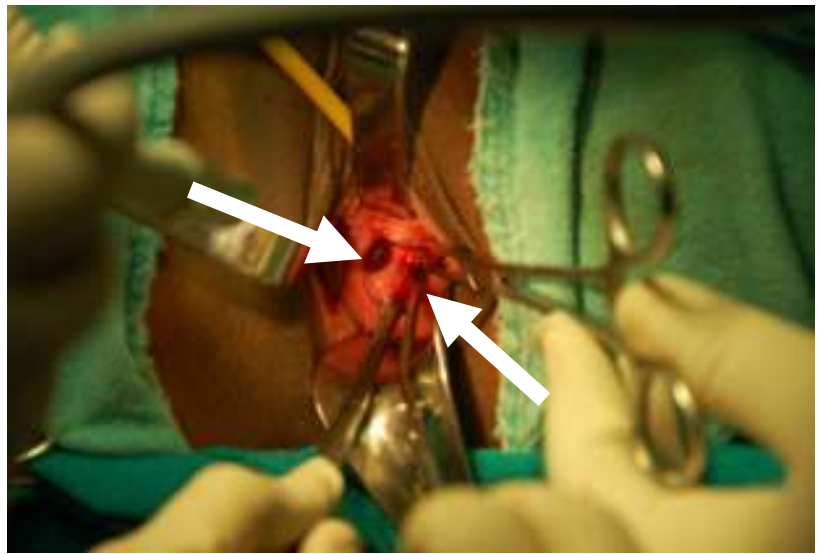

Figure 3: Intraoperative picture showing right haematocolpos (arrow) with normal left hemivagina and cervix (with uterine sound shown by below arrow). 


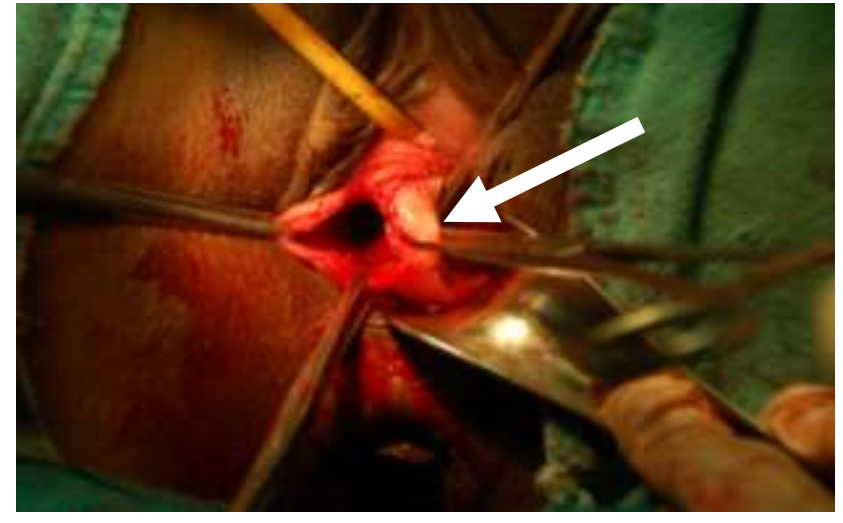

Figure 4: Intraoperative picture showing spontaneously ruptured right haematocolpos with normal left hemivagina and left cervix (arrow).

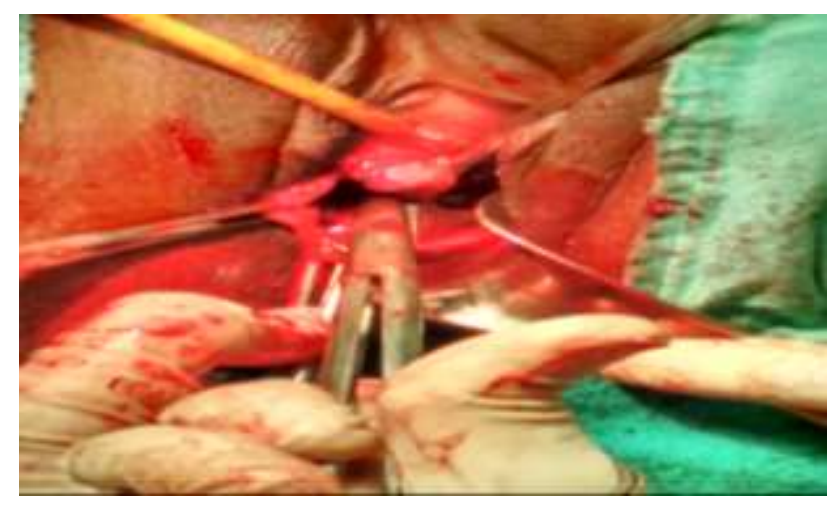

Figure 5: Intraoperative picture showing right vaginal septal resection.

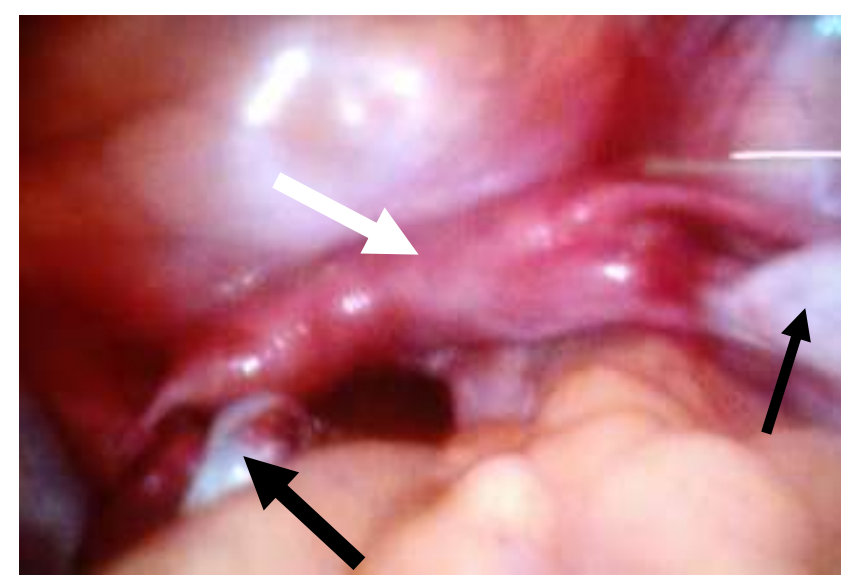

Figure 6: Laparoscopic picture showing uterus didelphys (arrow) with bilateral normal tubes and ovaries (black arrows).

\section{DISCUSSION}

The specific association of uterus didelphys, an obstructed hemivagina and an ipsilateral absent kidney was first described by Wilson in $1925 .^{1}$

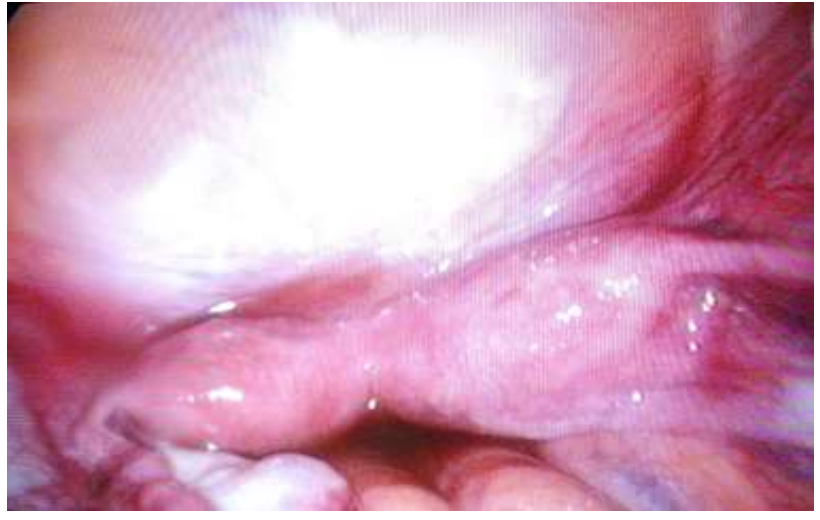

Figure 7: Laparoscopic picture showing uterus didelphys with normal pouch of Douglas and urinary bladder.

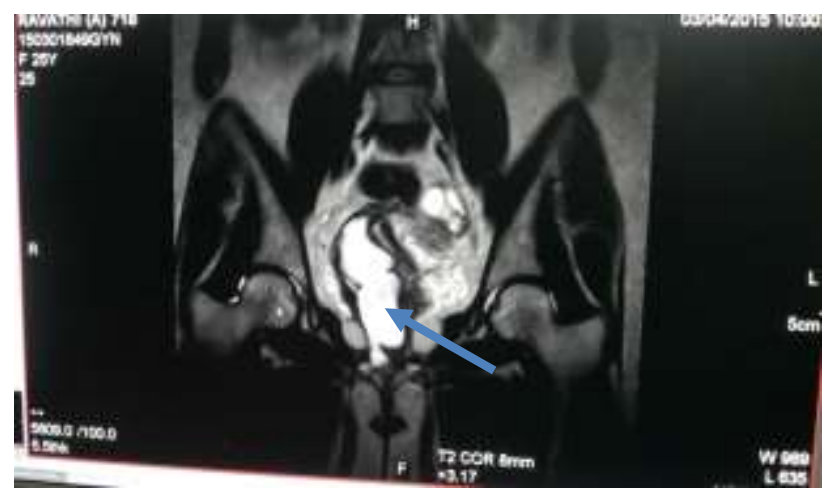

Figure 8: MRI picture showing obstructed right hemivagina with hematometrocolpos (blue arrow) \& normal left hemivagina.

Since then, such cases were reported to have clinical presentations of cyclical vaginal mass, hematocolpos, dyspareunia, acute abdominal pain $^{3}$ and intermenstrual bleeding. ${ }^{4}$ Most of the mullerian anomalies are detected when patients present with primary amenorrhea, primary infertility or cyclical dysmenorrhea in the peripubertal age or dyspareunia in the marital life.

In the present case, the late presentation of hematocolpos of imperforate right hemivagina was due to the presence of a pinhole opening in the existing longitudinal septum with the slow drainage of menstrual bleed and recent occlusion of this opening due to infection.

This patient had lateral fusion defect of both symmetrical type (uterus didelphys) and asymmetrical type (unilateral obstruction of septate vagina). ${ }^{8}$ Ipsilateral kidney is absent in most cases with asymmetrical lateral fusion defects. ${ }^{8}$

Methods for resection of vaginal septum have been proposed and successful term pregnancy after resection has been reported. ${ }^{2-6}$ 
Septal resection reduces chances of hematocolpos, pyocolpos, dyspareunia and improves fertility as sperms can migrate through both cervices. ${ }^{8}$

Use of 3D sonography for the diagnosis of mullerian anomalies was explored by Salim et al. ${ }^{7}$

\section{CONCLUSION}

Mullerian duct anomalies are a morphologically diverse group of congenital disorders involving the female reproductive tract. A septate/double vagina may occur in isolation if canalization of the most caudal part of the fused mullerian duct is incomplete. ${ }^{4}$ Some of these anomalies are atypical and do not fit exactly into any class of American Fertility Society classification.

Establishing a correct diagnosis is essential for planning treatment and management strategies. ${ }^{4}$ The surgical correction of mullerian anomalies is case specific and success of surgery is gauged by patient's postoperative ability to have healthy sexual life and successful reproductive outcome. ${ }^{3,4}$

Funding: No funding sources Conflict of interest: None declared

Ethical approval: Not required

\section{REFERENCES}

1. Wilson JS. A case of double uterus and vagina with unilateral hematocolpos and hematometra-journal of obstetrics gynaecology, British empire.1925;32;1278 .

2. Candiani GB, Fedale L, Candiani M. Double uterus, blind hemivagina and ipsilateral renal agenesis, 36 cases and long term followup- obstetrics and gynecology. 1997;90:26-32.

3. Hill RM -uterus didelphys with hematocolpos and hematometra on one side and normal menses from the other - report of an unusual case -Journal international college of surgery. 1958;29:422-8.

4. Purandare CN, Umrigar R, Bandukwalla V. Case report of hematometra in uterus didelphys with right hemivagina and right renal agenesis--journal of obstetrics and gynecology in India. 2011;61,2:21012.

5. Rock JA, Jones HW. Double uterus associated with an obstructed hemivagina and ipsilateral renal agenesis-American journal of obstetrics and gynecology.1980;138:339-42.

6. Allan N, Cowan, LE-uterus didelphys with unilateral imperforate vagina-report of 4 cases, obstetrics and gynecology. 1963;22:422-6 .

7. Salim R, Wolfer B, Backos M. Reproducibility of 3 dimensional ultrasound diagnosis of congenital uterine anomalies - ultrasound obstetrics and gynecology. 2003;21;578-2.

8. Kumari BP. Embryology of female genital tract and its congenital anomalies, Postgraduate Gynaecology, $1^{\text {st }}$ edition; 2011;20-1.

Cite this article as: Kothapally KR, Kavati V, Murthy NVR, Biswas S, Panditi S. Wunderlich Herlyn: Werner syndrome. Int J Reprod Contracept Obstet Gynecol 2016;5:562-5. 